OPEN ACCESS

Edited by:

Pamela Menegazzi,

University of Wuerzburg, Germany

Reviewed by:

Audrey Mat,

Institut Français de Recherche pour

l'Exploitation de la Mer, France

*Correspondence:

David Wilcockson

dqw@aber.ac.uk

Specialty section:

This article was submitted to Chronobiology,

a section of the journal

Frontiers in Physiology

Received: 06 December 2021 Accepted: 04 February 2022

Published: 25 February 2022

Citation:

Rock A, Wilcockson D and

Last KS (2022) Towards an

Understanding of Circatidal Clocks.

Front. Physiol. 13:830107.

doi: 10.3389/fphys.2022.830107

\section{Towards an Understanding of Circatidal Clocks}

\author{
Alberto Rock ${ }^{1}$, David Wilcockson ${ }^{2 *}$ and Kim S. Last ${ }^{1}$ \\ 'Department of Science, Scottish Association for Marine Science, Oban, United Kingdom, ${ }^{2}$ Institute of Biological, \\ Environmental, and Rural Sciences, Aberystwyth University, Aberystwyth, United Kingdom
}

Circadian clocks are an intrinsic element of life that orchestrate appropriately timed daily physiological and behavioural rhythms entrained to the solar cycle, thereby conferring increased fitness. However, it is thought that the first archaic 'proto-clocks' evolved in ancient cyanobacteria in a marine environment, where the dominant time cues (zeitgebers) probably would have been lunar-driven and included tidal cycles. To date, non-circadian 'marine clocks' have been described with circatidal ( 12.4h), circasemilunar ( 14.8 days), and circalunar ( $\sim 29.5$ days) periodicity, mostly studied in accessible but temporally complex intertidal habitats. In contrast to the well-described circadian clock, their molecular machinery is poorly understood, and fundamental mechanisms remain unclear. We propose that a multi-species approach is the most apposite strategy to resolve the divergence that arose from non-circadian clockwork forged in an evolutionary environment with multiple zeitgebers. We review circatidal clock models with a focus on intertidal organisms, for which robust behavioural, physiological, or genetic underpinnings have been explicated, and discuss their relative experimental merits. Developing a comprehensive mechanistic understanding of circatidal clocks should be a priority because it will ultimately contribute to a more holistic understanding of the origins and evolution of chronobiology itself.

Keywords: circadian, circatidal, lunar, chronobiology, marine, intertidal, mechanistic understanding, evolution

\section{INTRODUCTION AND BACKGROUND}

For most of us, chronobiology is the study of the circadian clock in terrestrial species. However, life evolved in our oceans, harbouring a tremendous diversity of organisms and some of the most dynamic and extreme ecosystems on Earth. This has led to dramatic zonation of species and habitats (Dudgeon et al., 1999; Hofmann, 2001) which are highly temporo-spatially variable. Links between chronobiology and ecology are apparent but often underexplored regarding temporal plasticity and the concept of 'chronotype', which define the characteristic temporal properties of organisms and are the targets of selection 
(Helm et al., 2017). Warming oceans, especially at high latitudes, are driving habitat range expansion (Poloczanska et al., 2016) and exposure to different seasonal patterns of entrainment (and thermal/photoperiodic mismatches), limiting entrainment (Schmal et al., 2020) or setting up potential barriers of migrations (Huffeldt, 2020). Investigating marine clocks using the right approaches and tools (Mat, 2019) provides an understanding of clock flexibility/lability and ultimately may be relevant to even our own behaviour and behavioural disorders, such as sleep and mood, when considering the interplay of different, or disrupted, rhythms in single organisms (Häfker and Tessmar-Raible, 2020). This mini-review will focus on circatidal clocks most studied in intertidal animals, their origins, their zeitgebers, diversity, and future research directions. We do not describe the molecular cogs of circadian clocks for which there are many excellent reviews (e.g., Zheng and Sehgal, 2012). Similarly, circalunar clocks have been comprehensively reviewed elsewhere (Andreatta and Tessmar-Raible, 2020) and will only be fleetingly covered.

\section{What Is the Evolutionary History of Circatidal Clocks?}

To understand the clocks of marine organisms, we must appreciate the origins of the circadian clock. There is a line of evidence, based on the evolutionary genomics of the kaiA, $k a i B$, and $k a i C$ gene cluster in blue green algae, that suggests our ancient ancestors, the cyanobacteria, may have utilised a proto-clock as long as 2.5 billion ( $\mathrm{Ga}$ ) years ago (Tauber et al., 2004). The marine unicellular cyanobacterium Prochlorococcus is the most abundant and ancient photosynthetic organism on Earth, with ancestral lineages found in the fossil record $\sim 3.2 \mathrm{Ga}$ (Heubeck, 2009) that were adapted to low-oxygen, low-light, and high-nutrient conditions. Prochlorococcus evolved chlorophyll machinery and retained phycobilisomes, protein assemblages capable of absorbing light efficiently in generating energy and oxygen (Ulloa et al., 2021). Together with their freshwater relatives Synechococcus, Prochlorococcus is not only credited for oxygenating the planet $\sim 2.3 \mathrm{Ga}$ but was also the first to evolve a functioning biological clock (Golden et al., 1997). In both species, the clock consists of proteins KaiA, KaiB, and KaiC, with $24 \mathrm{~h}$ oscillations of KaiC phosphorylation persisting in vitro. It is suggested that possessing this endogenous timer may have been crucial in anticipating environmental extremes with active motile avoidance at a time when the atmosphere permitted significant UV radiation at the water's surface (Pittendrigh, 1993; Hoiczyk, 2000).

By the time the first Eukaryotes emerged a billion years later, the stage was set for the rise of the modern transnuclear circadian clock. Putative early multicellular organisms, such as Grypania, probably either a bacterial colony or an alga (Han and Runnegar, 1992), may have been the first to evolve a clock, now mirrored in contemporary marine algae such as Acetabularia. Furthermore, the temporal environment in which the proto-clock evolved would have been very different to the present day. During the time of the first Eukaryotes 2.7-1.6 Ga, the rotational period of the earth is estimated to have been between 13.5 and $4 \mathrm{~h}$ (Krasinsky, 2002)! Given that the current circadian period is $24 \mathrm{~h}$, the molecular clock must have had the flexibility to adapt to a changing zeitgeber and opens the question: how may this proto-clock have evolved and diversified through these geological timescales? We can say with some certainty (but little evidence) that since the first proto-clocks evolved in an aquatic environment, we should examine the marine environment for clues to the early evolution of chronobiology, including the deep-sea, considered analogous to regions of the primitive ocean (Mat et al., 2020), and investigate whether circatidal clocks are the precursors to the circadian clock (Wilcockson and Zhang, 2008). To do so, we should first consider the cyclic complexity of the marine realm.

\section{Cyclic Complexity of Intertidal Environments}

The intertidal zone is dominated by the relentless ebb and flow of the tides, which vary in magnitude and range depending on seasonality, atmospheric conditions, and geography. Abiotic cycles linked to tidal movements include salinity, $\mathrm{pH}$, temperature, turbidity, nutrient availability, and hydrostatic pressure, as well as diel, lunar, and seasonal events which superimpose on these dramatic changes (de la Iglesia and Johnson, 2013), each carrying ecological implications (Figure 1). These cycles are driven by gravitational and centrifugal forces of the Earth and moon spinning around a common centre of gravity and modulated by the gravitational effects of the sun over the annual cycle. The lunar day (the time it takes the earth to complete one revolution beneath the moon) takes $24.8 \mathrm{~h}$ and results in a single diurnal tide, i.e., as found in the Caribbean Sea or, more commonly, two high and low tides a day known as semidiurnal tides, with a period of $\sim 12.4 \mathrm{~h}$. When the sun and moon align (full and new moon), their combined gravity generates larger 'spring' tides, and when at $90^{\circ}$ relative to the earth (quarter moons), generate smaller 'neap' tides. These are known as semilunar tides, with a period of $\sim 14.8$ days, repeated every $\sim 29.5$ days but under a full moon (i.e., light at night) as the lunar cycle.

\section{What Is the Evidence for Circatidal Clocks?}

Circatidal (12.4h) rhythms were first observed in the intertidal acoel worm Symsagittifera (formerly Convoluta) roscoffensis by Gamble and Keeble (1903). After collecting the animals from the shore into laboratory tanks the researchers noted: 'After a spell of insolation, colonies sink below the surface [of the sand], and after a certain sojourn in darkness they return to the surface. These movements synchronise with the covering and uncovering of the Convoluta zone by the tides'. The worms' innate ability to anticipate the tidal cycle enabled predictive downward migrations into the sand even when removed from the shore. Later, several studies revealed similar behaviour under constant conditions in a number of other marine organisms including molluscs (Brown et al., 1954; Morton, 1977) and 


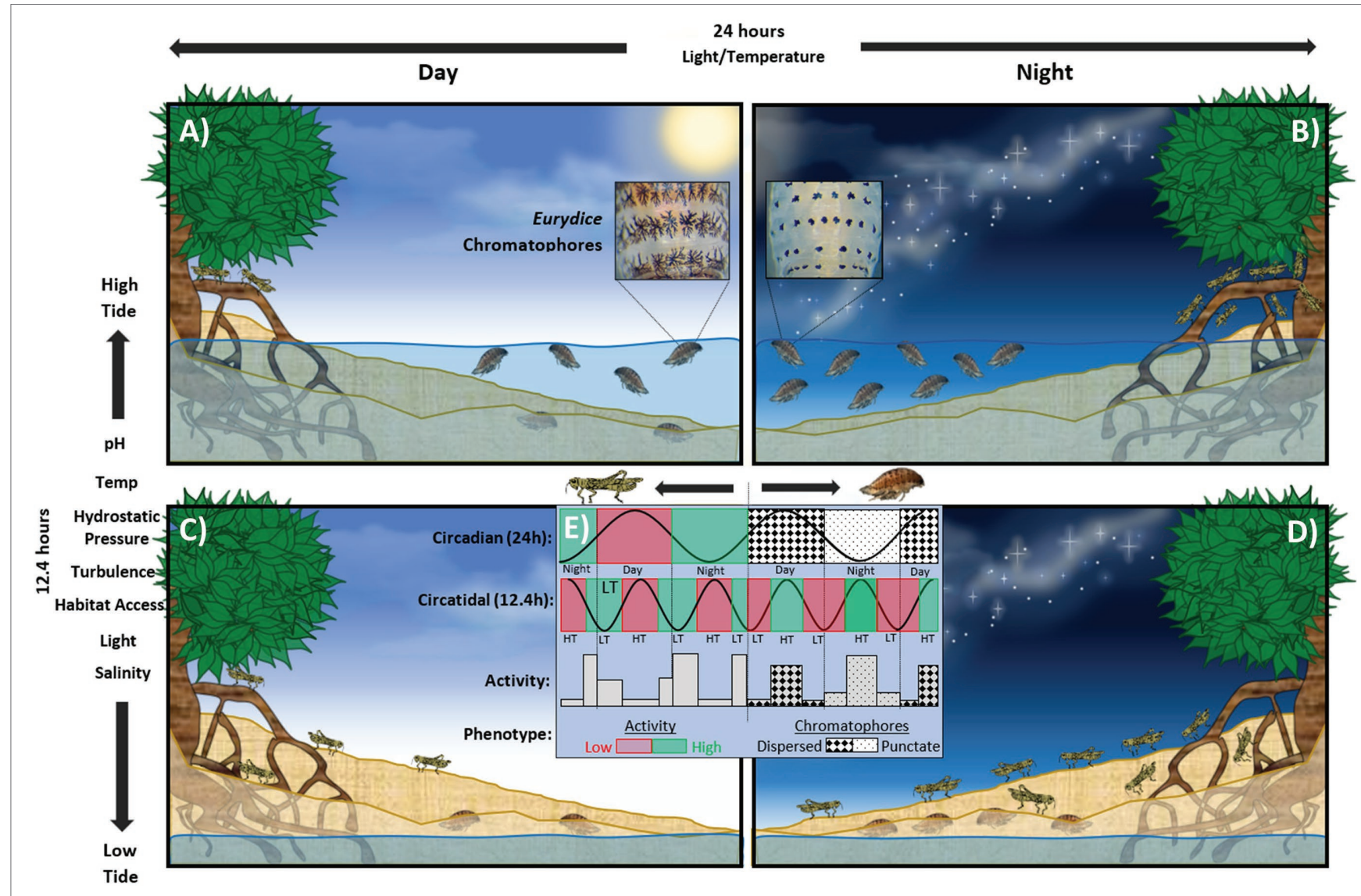

FIGURE 1 | Representation of clocks of the speckled sea louse, Eurydice pulchra and the mangrove cricket Apteronemobius asahinai on a hypothetical shore. (A) Diurnal high tide; Eurydice appears more pigmented (circadian behaviour) and is active in the water column (circatidal behaviour). Apteronemobius is active (circadian) but does not forage (circatidal). (B) Nocturnal high tide; Eurydice appears less pigmented but is very active in the water column. Apteronemobius is not active. (C) Diurnal low tide; Eurydice appears pigmented but is buried in the sand. Apteronemobius is actively foraging on the shore. (D) Nocturnal low tide; Eurydice appears less pigmented and is buried. Apteronemobius is active but does not forage. (E) Summary of phenotypes as they relate to the circadian and circatidal cycles. Principle environmental zeitgebers for circatidal and circadian rhythms shown to the left and above panels, respectively.

crustaceans (Enright, 1963; Morgan, 1965; Barnwell, 1966; Jones and Naylor, 1970). Naylor (1958) conducted a seminal study which demonstrated circatidal behaviour in the crab Carcinus maenas but modulated by a circadian 'suppressor' of activity. This revealed that such rhythms were generated endogenously without external stimulus in the laboratory. In the following years, more work contributed to the diversity of marine taxa displaying biological rhythms (see Naylor, 2010). Other classic examples of circatidal behaviours include locomotory and metabolic activity in the isopod Eurydice pulchra (Hastings, 1981a; Wilcockson and Zhang, 2008; O’Neill et al., 2015) and foraging behaviour in the mangrove cricket, Apteronemobius asahinai (Satoh et al., 2008; see Figure 1).

\section{How Are Circatidal Clocks Entrained?}

The greatest difference between marine and terrestrial (predominantly circadian) clocks is in the mode and mechanism of entrainment. The marine component of circasemilunar rhythmicity in Clunio marinus, for example, is entrained by tidal cycles of temperature and mechanical disturbance (Neumann, 1978). Conversely in the congener Clunio tsushimensis, circasemilunar rhythmicity is entrained by moonlight and is suspected to be driven by an endogenous circasemilunar oscillator (Neumann, 1988, 2014). That the circasemilunar mechanisms in two species of midge from the same genus are entrained by different stimuli supports the putative diversity of marine clocks; if not in the fundamental clockwork, then at least the transducer linking environmental stimuli to the endogenous oscillator. Circatidal swimming in E. pulchra conversely (Figure 1) is likely entrained by a combination of synchronised wave action or vibration (turbulence) and variation in hydrostatic pressure as associated with benthic dwellers covered by different depths of water over a tidal cycle (Jones and Naylor, 1970; Hastings, 1981b; Zhang et al., 2013). Common tidal zeitgebers include $\mathrm{pH}$, temperature, salinity and hydrostatic pressure (Reid and Naylor, 1990), vibration (Zhang et al., 2013), air/water exposure (Williams and Naylor, 1969), turbulence (Klapow, 1972; Neumann and Heimbach, 1984; Reid and Naylor, 1986), habitat access and immersion cycles (Chabot et al., 2008), and food pulses (Williams and Pilditch, 1997), which all vary cyclically with the tides (Figure 1). 


\section{How Have Circatidal Rhythms Been Explained?}

At a mechanistic level, there are several hypotheses which aim to address this question from different angles (Kim et al., 2003). Enright (1976) first proposed the bimodal clock hypothesis in which a single oscillator commands both circatidal and circadian rhythms, depending on the dominant zeitgeber (Enright, 1976). Such a clock could be fundamentally circadian, but entrainable by tidal zeitgebers such as water current. Indeed, it has been shown that in the oyster, Crassostrea gigas, tidal rhythms can be entrained by $6 \mathrm{~h}$ of light and dark cycles with circadian rhythms entrained by water current cycles (Mat et al., 2012, 2014).

While the bimodal clock hypothesis is simple in that it abrogates the need for dual endogenous oscillators, Palmer (1995) and Naylor (1996) each proposed mechanisms to reconcile circadian and circatidal rhythms. Palmer (1995) proposed the Circalunidian Clock Hypothesis, while Naylor (1996) the Circatidal/Circadian-Clock Hypothesis. Palmer tendered that in the fiddler crab Uca pugnax, circatidal behaviours are the effect of dual circalunidian clocks with a period of $\sim 24.8 \mathrm{~h}$ coupled in antiphase, while Naylor argued that these behaviours were better explained by the interaction of a $\sim 24 \mathrm{~h}$ circadian clock and a distinct $\sim 12.4 \mathrm{~h}$ circatidal clock, at least in the green crab Carcinus maenas. While both hypotheses have their merits, there has been mounting evidence supporting the latter including the independent disruption of the circadian rhythm, while leaving circatidal behaviour unaffected in both E. pulchra and A. asahinai (Takekata et al., 2012, 2014a,b; Zhang et al., 2013).

Separate circadian and circatidal clockwork, as proposed by Naylor, also provide an explanation for seemingly endogenous semilunar rhythms, given their natural harmonic relationship; the Beat Hypothesis (Bünning and Müller, 1961) states that independent circadian and circatidal clocks would come into phase every $\sim 14.8$ days thereby generating a circasemilunar rhythm of behaviour coincident with the spring/neap tidal cycle (Neumann, 2014; Kaiser and Neumann, 2021). Tidalrelated rhythms may also emerge where sensitivity to an exogenous stimulus is regulated by the circadian clock, explained by the Coincidence Detection Hypothesis (Kaiser and Neumann, 2021). Tidal turbulence is strongest during the rising high tide, which occurs at the same time of day every $\sim 14.8$ days. Therefore, if the circadian clock was to regulate the sensitivity of turbulence receptors to engage at a consistent time of day, the turbulence of the rising tide would be detected once every $\sim 14.8$ days and produce a circasemilunar stimulus (Kaiser and Neumann, 2021).

\section{DISCUSSION}

The nature of circatidal clocks has been extrapolated from overt behavioural rhythms in many marine organisms over the last century (see Naylor, 2010). The value of behavioural studies in describing rhythmic phenotypes controlled by the circatidal clockwork is undeniable, but a definitive mechanistic model of the core tidal oscillator and entrainment pathways is needed. To establish a testable mechanistic model of the circatidal clockwork, contemporary functional molecular and cellular approaches must be used against the rich backdrop of rhythmic tidal phenotypes, and across multiple species.

\section{How Do We Decipher the Molecular Basis of Circatidal Clocks?}

Genomic and transcriptomic datasets on circadian 'clock genes' in rhythmic marine species have provided insights to the relationships between species and the temporal expression profiles of whole transcriptomes, yet functional analyses are lacking (with a few exceptions, see below), and with few attempts at deciphering how tidal (and semilunar and lunar) clocks actually work. For example, functional and loss of function strategies applied to marine species include in vivo genome/transcription manipulation and mutagenesis-RNA interference (Takekata et al., 2012, 2014a; Zhang et al., 2013; Payton et al., 2017), transcriptional activator-like effector nucleases (TALENs; Bannister et al., 2014), and rhythmic phenotype rescue in transgenic flies expressing clock, or clockassociated genes from marine animals (Beckwith et al., 2011; Zhang et al., 2013). Pharmacological perturbation of clock biochemistry (such as casein kinase inhibition), clock cell localisation (in situ hybridisation and immunochemical detection) and in vitro cell-based protein interaction assays (such as fly S2 cell systems) have been used to shed light on the role of canonical circadian genes in tidal and lunar rhythmicity (Zantke et al., 2013; Zhang et al., 2013). The paucity of functional studies on circatidal clocks likely reflects that organisms exhibiting robust, persistent and observable phenotypes lack tried and tested, species-specific and validated laboratory reagents or, in many cases, genomes. Many marine species also exhibit complex lifecycles, usually with planktonic phases, that make genome editing a significant challenge.

Nevertheless, it is increasingly evident that non-model systems are essential in revealing the nature and evolution of clocks and so called 'wild clocks' have emerged as a fertile ground for research (Schwartz et al., 2017). The breadth of marine species explored for their rhythmicity represents an exciting platform for targeted mechanistic approaches to gain insight to circatidal clock function. To facilitate this, good models should have some key attributes: a reliable and measurable circatidal phenotype (due to the inherent variability in tidal cues and to decipher between daily and truly tidal rhythms); genetic and experimental tractability; availability, accessibility, and simple husbandry.

Several suitable candidate non-model organisms have been identified. For example, E. pulchra has been shown to exhibit robust, entrainable phenotypes and is relatively content in experimental settings. However, its protracted development means that genome editing is challenging. Apteronemobius asahinai also shows promise as a tidal model (Satoh and Terai, 2019) and has a recently published draft genome (Satoh et al., 2021). Other models include an intertidal limpet (Schnytzer et al., 2018) and bivalves (Connor and Gracey, 2012; 
Mat et al., 2012, 2014, 2016; Gracey and Connor, 2016; Payton et al., 2017) but for the limpet in particular, individual, entrainable phenotypes are not as easily measured as for more mobile animals that lend themselves to infra-red beam monitoring. Therefore, energies and resources across multiple emerging model species are necessary; each model has its merits, and it is a tantalising prospect that concerted and collaborative efforts might yield deep insight into the evolution of the circatidal clockwork.

Circadian genes have been the focus of tidal and lunar clock research until now and there is evidence that dominant cycles of the organism (Mat et al., 2016, 2020; Tran et al., 2020), or even the demands of photosynthetic symbionts (in the case of the coral, Aiptasia diaphana), shape tidal or daily gene expression (Sorek et al., 2018). Such studies are intriguing but do not directly address the functional basis of circatidal phenotypes. In parallel with the manipulation of circatidal genomes to dissect the tidal clock (Takekata et al., 2012, 2014a; Zhang et al., 2013; Payton et al., 2017), efforts might also focus on identifying regulatory elements of tidally rhythmic gene transcription (tidally responsive DNA enhancers; TyDEs; O'Neill et al., 2015). These are suggested for nuclear expression of mitochondrial transcription factors in E. pulchra and were revealed by examination of metabolic markers of tidal activity. The recent discovery of a cellautonomous $12 \mathrm{~h}$ murine clock regulated by the spliced form of X-box Binding Protein 1 (XBP1s) is interesting because $\mathrm{XBP} 1 s-d$ riven rhythms of transcription are distinct and independent from the circadian clock. This feature resonates with the notion of independent circadian and tidal clocks. Moreover, XBP1s are conserved through evolution and have been described in some marine species (Pan et al., 2020; Tong et al., 2021); analysis of $12 \mathrm{~h}$ cycling transcripts in two intertidal species, the anemone Aiptasia diaphana and limpet Cellana rota, revealed significant overlap with $12 \mathrm{~h}$ cycling transcripts in mice (Pan et al., 2020).

\section{Where Is the Circatidal Clockwork?}

The hypothesis that some tidal (and indeed, lunar) clocks are distinct from the circadian clock (Reid and Naylor, 1989; Takekata et al., 2012, 2014a,b; Zantke et al., 2013; Zhang et al., 2013; Satoh, 2017) raises questions about the physical interactions of clock cells with different periods and whether discrete subsets of neurons interact to drive circatidal phenotypes. There have been remarkably few attempts to describe the neuroarchitecture of clocks in lunar and tidal organisms with efforts hampered by the current lack of bonafide tidal candidate genes or proteins to target. Some reagents, including antisera to circadian proteins, have been generated specifically for circatidal marine species such as E. pulchra (Zhang et al., 2013), while heterologous sera have been used to describe the brain regions expressing circadian neuropeptides or proteins in the mangrove cricket (Takekata et al., 2014b) and crabs (Beckwith et al., 2011). Attempts at isolating the cellular foci of tidal clocks using optic lobe ablation in the mangrove cricket have been reported and corroborate the notion of separate tidal and daily clocks (Takekata et al., 2014b).
Efforts to generate and collaboratively share resources for cell localisation and functionality would be well rewarded.

\section{Understanding Circatidal Entrainment Mechanisms}

The diversity of zeitgebers in coastal habitats offers the opportunity to explore how these environmental signals are transduced into the oscillator(s) of tidal organisms, a relatively untouched area of marine chronobiology; indeed, environmental perception per se in marine animals is poorly researched. For example, E. pulchra entrain to cycles of vibration or mechanical stimulation and Drosophila chordotonal organs, peripheral mechano-receptors, have been linked to the circadian entrainment via periodic vibration (Simoni et al., 2014) and temperature (Sehadova et al., 2009). A recent, elegant study on Platynereis dumerilii segmentally iterated r-opsin expressing peripheral sensory cells demonstrated dual photo and non-photosensory (mechanosensory) roles. Here, mechanosensory roles of the r-opsin receptors may have evolved secondarily to light receptors (Revilla-I-Domingo et al., 2021). Exploration of entrainment pathways from receptor to oscillator in other evolutionarily ancient marine species might yield important comparative outcomes with relevance to extant circadian systems.

\section{CONCLUSION}

The first molecular proto-clocks probably evolved in the same organisms which paved the way for all aerobic life by oxygenating Earth's atmosphere. These adapted to an everchanging cyclic environment over geological timescales, including lengthening of the diel cycle. In the last century, many marine behavioural rhythms have been identified and multiple mechanisms suggested. Now, the rapid advance of powerful cellular and molecular methods has equipped chronobiologists with the necessary tools to reveal the clockwork in non-model marine organisms. Only through collaborative and interdisciplinary research linking marine biologists, molecular and cellular biologists, and neuroscientists, will we achieve a holistic understanding of the evolution, mechanism, and principles of the circatidal clock.

\section{AUTHOR CONTRIBUTIONS}

All authors listed have made a substantial, direct, and intellectual contribution to the work, and approved it for publication.

\section{FUNDING}

This work was supported by the CHASE project, part of the Changing Arctic Ocean (CAO) programme, jointly funded by the UKRI Natural Environment Research Council (NERC, project number: NE/R012733/1) and the German Federal Ministry of Education and Research (BMBF, project number: 03F0803A). Additional funding was provided by the CAO project Arctic PRIZE (NE/P006302/1). 


\section{REFERENCES}

Andreatta, G., and Tessmar-Raible, K. (2020). The still dark side of the moon: molecular mechanisms of lunar-controlled rhythms and clocks. J. Mol. Biol. 432, 3525-3546. doi: 10.1016/j.jmb.2020.03.009

Bannister, S., Antonova, O., Polo, A., Lohs, C., Hallay, N., Valinciute, A., et al. (2014). TALENs mediate efficient and heritable mutation of endogenous genes in the marine annelid Platynereis dumerilii. Genetics 197, 77-89. doi: 10.1534/genetics.113.161091

Barnwell, F. H. (1966). Daily and tidal patterns of activity in individual fiddler crab from the woods hole region. Biol. Bull. 130, 1-17. doi: 10.2307/1539948

Beckwith, E. J., Lelito, K. R., Hsu, Y.-W. A., Medina, B. M., Shafer, O., Ceriani, M. F., et al. (2011). Functional conservation of clock output signalling between flies and intertidal crabs. J. Biol. Rhythm. 26, 518-529. doi: $10.1177 / 0748730411420242$

Brown, F. A., Webb, H. M., Bennett, M. F., and Sandeen, M. I. (1954). Temperature-independence of the frequency of the endogenous tidal rhythm of Uca. Physiol. Zool. 27, 345-349. doi: 10.1086/physzool.27.4.30152370

Bünning, E., and Müller, D. (1961). Wie messen organismen lunare zyklen? Z. Naturforsch. B 16, 391-395. doi: 10.1515/znb-1961-0609

Chabot, C., Skinner, S., and Watson, W. (2008). Rhythms of locomotion expressed by Limulus polyphemus, the American horseshoe crab: I. synchronization by artificial tides. Biol. Bull. 215, 34-45. doi: 10.2307/25470681

Connor, K., and Gracey, A. (2012). High-resolution analysis of metabolic cycles in the intertidal mussel Mytilus californianus. Am. J. Phys. Regul. Integr. Comp. Phys. 302, 103-111. doi: 10.1152/ajpregu.00453.2011

de la Iglesia, H., and Johnson, C. (2013). Biological clocks: riding the tides. Curr. Biol. 23, 921-923. doi: 10.1016/j.cub.2013.09.006

Dudgeon, S. R., Steneck, R. S., Davison, I. R., and Vadas, R. L. (1999). Coexistence of similar species in a space-limited intertidal zone. Ecol. Monogr. 69, 331-352. doi: 10.1890/0012-9615(1999)069[0331:COSSIA]2.0.CO;2

Enright, J. T. (1963). The tidal rhythm of activity of a sand-beach amphipod. Z. Vergl. Physiol. 46, 276-313.

Enright, J. T. (1976). Plasticity in an isopod's clockworks: shaking shapes form and affects phase and frequency. J. Comp. Physiol. 107:13. doi: 10.1007/ BF00663916

Gamble, F. W., and Keeble, F. (1903). The bionomics of Convoluta Roscoffensis, with special reference to its green cells. Proc. R. Soc. Lond. 72, 93-98. doi: 10.1098/rspl.1903.0022

Golden, S. S., Ishiura, M., Johnson, C. H., and Kondo, T. (1997). Cyanobacterial circadian rhythms. Annu. Rev. Plant Physiol. Mol. Biol. 48, 327-354. doi: 10.1146/annurev.arplant.48.1.327

Gracey, A., and Connor, K. (2016). Transcriptional and metabolomic characterization of spontaneous metabolic cycles in Mytilus californianus under subtidal conditions. Mar. Genomics 30, 35-41. doi: 10.1016/j. margen.2016.07.004

Häfker, N. S., and Tessmar-Raible, K. (2020). Rhythms of behavior: are the times changin'? Curr. Opin. Neurobiol. 60, 55-66. doi: 10.1016/j. conb.2019.10.005

Han, T. M., and Runnegar, B. (1992). Megascopic eukaryotic algae from the 2.1-billion-year-old Negaunee iron-formation, Michigan. Science 257, 232-235. doi: $10.1126 /$ science. 1631544

Hastings, M. H. (1981a). Semi-lunar variations of endogenous circa-tidal rhythms of activity and respiration in the isopod Eurydice pulchra. Mar. Ecol. Prog. Ser. 4, 85-90.

Hastings, M. H. (1981b). The entraining effect of turbulence on the circa-tidal activity rhythm and its semi-lunar modulation in Eurydice pulchra. J. Mar. Biol. Assoc. U. K. 61, 151-160.

Helm, B., Visser, M., Schwartz, W., Kronfeld-Schor, N., Gerkema, M., Piersma, T., et al. (2017). Two sides of a coin: ecological and chronobiological perspectives of timing in the wild. Philos. Trans. R. Soc. B Biol. Sci. 372:20160246. doi: 10.1098/rstb.2016.0246

Helmuth, B. S., and Hofmann, G. E. (2001). Microhabitats, thermal heterogeneity, and patterns of physiological stress in the rocky intertidal zone. Biol. Bull. 201, 374-384. doi: $10.2307 / 1543615$

Heubeck, C. (2009). An early ecosystem of Archean tidal microbial mats (Moodies group, South Africa, 3.2 Ga). Geology 37, 931-934. doi: 10.1130/ G30101A.1
Hoiczyk, E. (2000). Gliding motility in cyanobacteria: observations and possible explanations. Arch. Microbiol. 174, 11-17. doi: 10.1007/s002030000187

Huffeldt, N. (2020). Photic barriers to poleward range-shifts. Trends Ecol. Evol. 35, 652-655. doi: 10.1016/j.tree.2020.04.011

Jones, D. A., and Naylor, E. (1970). The swimming rhythm of the sand beach isopod Eurydice Pulchra. J. Exp. Mar. Biol. Ecol. 4, 188-199. doi: 10.1016/0022-0981(70)90024-9

Kaiser, T. S., and Neumann, D. J. (2021). Circalunar clocks-old experiments for a new era. Bioessays 43:e2100074. doi: 10.1002/bies.202100074

Kim, W. S., Huh, H. T., Je, J. G., and Han, K. N. (2003). Evidence of twoclock control of endogenous rhythm in the Washington clam, Saxidomus purpuratus. Mar. Biol. 142, 305-309. doi: 10.1007/s00227-002-0952-0

Klapow, L. (1972). Natural and artificial rephasing of a tidal rhythm. J. Comp. Physiol. 79, 233-258. doi: 10.1007/BF00694219

Krasinsky, G. (2002). Dynamical history of the earth-moon system. Celest. Mech. Dyn. Astron. 84, 27-55. doi: 10.1023/A:1019955827459

Mat, A. (2019). Chronobiology and the design of marine biology experiments. ICES J. Mar. Sci. 76, 60-65. doi: 10.1093/icesjms/fsyl31

Mat, A., Massabuau, J. C., Ciret, P., and Tran, D. (2012). Evidence for a plastic dual circadian rhythm in the oyster Crassostrea gigas. Chronobiol. Int. 29, 857-867. doi: 10.3109/07420528.2012.699126

Mat, A., Massabuau, J., Ciret, P., and Tran, D. (2014). Looking for the clock mechanism responsible for circatidal behavior in the oyster Crassostrea gigas. Mar. Biol. 161, 89-99. doi: 10.1007/s00227-013-2317-2

Mat, A., Perrigault, M., Massabuau, J., and Tran, D. (2016). Role and expression of cryl in the adductor muscle of the oyster Crassostrea gigas during daily and tidal valve activity rhythms. Chronobiol. Int. 33, 949-963. doi: 10.1080/07420528.2016.1181645

Mat, A., Sarrazin, J., Markov, G., Apremont, V., Dubreuil, C., Eché, C., et al. (2020). Biological rhythms in the deep-sea hydrothermal mussel Bathymodiolus azoricus. Nat. Commun. 11:3454. doi: 10.1038/ s41467-020-17284-4

Morgan, E. (1965). The activity rhythm of the amphipod Corophium volutator (Pallas) and its possible relationship to changes in hydrostatic pressure associated with the tides. J. Anim. Ecol. 34, 731-746. doi: 10.2307/2459

Morton, B. S. (1977). The tidal rhythm of feeding and digestion in the Pacific oyster, Crassostrea gigas (Thunberg). J. Exp. Mar. Biol. Ecol. 26, 135-151. doi: 10.1016/0022-0981(77)90103-4

Naylor, E. (1958). Tidal and diurnal rhythms of locomotory activity in Carcinus maenas (L.). J. Exp. Biol. 35, 602-610. doi: 10.1242/jeb.35.3.602

Naylor, E. (1996). Crab clockwork: the case for interactive circatidal and circadian oscillators controlling rhythmic locomotor activity of Carcinus maenas. Chronobiol. Int. 13, 153-161. doi: 10.3109/07420529609012649

Naylor, E. (2010). Chronobiology of Marine Organisms. Cambridge: Cambridge University Press.

Neumann, D. (1978). Entrainment of a semilunar rhythm by simulated tidal cycles of mechanical disturbance. J. Exp. Mar. Biol. Ecol. 35, 73-85. doi: 10.1016/0022-0981(78)90091-6

Neumann, D. (1988). Temperature compensation of circasemilunar timing in the intertidal insect Clunio. J. Comp. Physiol. A. 163, 671-676. doi: 10.1007/ BF00603851

Neumann, D. (2014). "Timing in tidal, semilunar, and lunar rhythms," in Annual, Lunar, and Tidal Clocks: Patterns and Mechanisms of Nature's Enigmatic Rhythms. eds. H. Numata and B. Helm (Tokyo: Springer Japan), 3-24.

Neumann, D., and Heimbach, F. (1984). Time cues for semilunar reproduction rhythms in European populations of Clunio marinus. II. The influence of tidal temperature cycles. Biol. Bull. 166, 509-524. doi: $10.2307 / 1541158$

O’Neill, J. S., Lee, K. D., Zhang, L., Feeney, K., Webster, S. G., Blades, M. J., et al. (2015). Metabolic molecular markers of the tidal clock in the marine crustacean Eurydice pulchra. Curr. Biol. 25, R326-R327. doi: 10.1016/j. cub.2015.02.052

Palmer, J. (1995). Review of the dual-clock control of tidal rhythms and the hypothesis that the same clock governs both circatidal and circadian rhythms. Chronobiol. Int. 12, 299-310.

Pan, Y., Ballance, H., Meng, H., Gonzalez, N., Kim, S. M., Abdurehman, L., et al. (2020). 12-h clock regulation of genetic information flow by XBP1s. PLoS Biol. 18:e3000580. doi: 10.1371/journal.pbio.3000580 
Payton, L., Perrigault, M., Hoede, C., Massabuau, J., Sow, M., Huvet, A., et al. (2017). Remodelling of the cycling transcriptome of the oyster Crassostrea gigas by the harmful algae Alexandrium minutum. Sci. Rep. 7:3480. doi: 10.1038/s41598-017-03797-4

Pittendrigh, C. (1993). Temporal organization: reflections of a Darwinian clockwatcher. Annu. Rev. Physiol. 55, 17-54. doi: 10.1146/annurev. ph.55.030193.000313

Poloczanska, E., Burrows, M., Brown, C., Molinos, J. G., Halpern, B., Hoegh-Guldberg, O., et al. (2016). Responses of marine organisms to climate change across oceans. Front. Mar. Sci. 3:62. doi: 10.3389/fmars.2016.00062

Reid, D., and Naylor, E. (1986). An entrainment model for semilunar rhythmic swimming behaviour in the marine isopod Eurydice pulchra leach. J. Exp. Mar. Biol. Ecol. 100, 25-35. doi: 10.1016/0022-0981(86)90153-X

Reid, D. G., and Naylor, E. (1989). Are there separate circatidal and circadian clocks in the shore crab Carcinus maenas? Mar. Ecol. Prog. Ser. 52, 1-6. doi: 10.3354/meps052001

Reid, D. G., and Naylor, E. (1990). Entrainment of bimodal circatidal rhythms in the shore crab Carcinus maenas. J. Biol. Rhythm. 5, 333-347. doi: 10.1177/074873049000500405

Revilla-I-Domingo, R., Rajan, V. B. V., Waldherr, M., Prohaczka, G., Musset, H., Orel, L., et al. (2021). Characterization of cephalic and non-cephalic sensory cell types provides insight into joint photo- and mechanoreceptor evolution. eLife 10:e66144. doi: 10.7554/eLife.66144

Satoh, A. (2017). Constant light disrupts the circadian but not the circatidal rhythm in mangrove crickets. Biol. Rhythm. Res. 48, 459-463. doi: 10.1080/09291016.2016.1275392

Satoh, A., Takasu, M., Yano, K., and Terai, Y. (2021). De novo assembly and annotation of the mangrove cricket genome. BMC. Res. Notes 14:387. doi: 10.1186/s13104-021-05798-Z

Satoh, A., and Terai, Y. (2019). Circatidal gene expression in the mangrove cricket Apteronemobius asahinai. Sci. Rep. 9:3719. doi: 10.1038/s41598-019-40197-2

Satoh, A., Yoshioka, E., and Numata, H. (2008). Circatidal activity rhythm in the mangrove cricket Apteronemobius asahinai. Biol. Lett. 4, 233-236. doi: 10.1098/rsbl.2008.0036

Schmal, C., Herzel, H., and Myung, J. (2020). Clocks in the wild: entrainment to natural light. Front. Physiol. 11:272. doi: 10.3389/fphys.2020.00272

Schnytzer, Y., Simon-Blecher, N., Li, J., Ben-Asher, H. W., Salmon-Divon, M., Achituv, Y., et al. (2018). Tidal and diel orchestration of behaviour and gene expression in an intertidal mollusc. Sci. Rep. 8:4917. doi: 10.1038/ s41598-018-23167-y

Schwartz, W. J., Helm, B., and Gerkema, M. P. (2017). Wild clocks: preface and glossary. Philos. Trans. R. Soc. Lond. Ser. B Biol. Sci. 372:20170211. doi: 10.1098/rstb.2017.0211

Sehadova, H., Glaser, F. T., Gentile, C., Simoni, A., Giesecke, A., Albert, J. T., et al. (2009). Temperature entrainment of Drosophila's circadian clock involves the gene nocte and signalling from peripheral sensory tissues to the brain. Neuron 64, 251-266. doi: 10.1016/j.neuron.2009.08.026

Simoni, A., Wolfgang, W., Topping, M. P., Kavlie, R. G., Stanewsky, R., and Albert, J. T. (2014). A mechanosensory pathway to the Drosophila circadian clock. Science 343, 525-528. doi: 10.1126/science.1245710

Sorek, M., Schnytzer, Y., Ben-Asher, H. W., Caspi, V. C., Chen, C. S., Miller, D. J., et al. (2018). Setting the pace: host rhythmic behaviour and gene expression patterns in the facultatively symbiotic cnidarian Aiptasia are determined largely by Symbiodinium. Microbiome 6:83. doi: 10.1186/ s40168-018-0465-9

Takekata, H., Matsuura, Y., Goto, S. G., Satoh, A., and Numata, H. (2012). RNAi of the circadian clock gene period disrupts the circadian rhythm but not the circatidal rhythm in the mangrove cricket. Biol. Lett. 8, 488-491. doi: $10.1098 /$ rsbl.2012.0079

Takekata, H., Numata, H., and Shiga, S. (2014b). The circatidal rhythm persists without the optic lobe in the mangrove cricket Apteronemobius asahinai. J. Biol. Rhythm. 29, 28-37. doi: 10.1177/0748730413516309

Takekata, H., Numata, H., Shiga, S., and Goto, S. G. (2014a). Silencing the circadian clock gene clock using RNAi reveals dissociation of the circatidal clock from the circadian clock in the mangrove cricket. J. Insect Physiol. 68, 16-22. doi: 10.1016/j.jinsphys.2014.06.012

Tauber, E., Last, K., Olive, P., and Kyriacou, C. (2004). Clock gene evolution and functional divergence. J. Biol. Rhythm. 19, 445-458. doi: $10.1177 / 0748730404268775$

Tong, Y., Mukhamejanova, Z., Zheng, Y., Wen, T., Xu, F., and Pang, J. (2021). Marine-derived xyloketal compound ameliorates MPP+-induced neuronal injury through regulating of the IRE1/XBP1 signalling pathway. ACS Chem. Neurosci. 12, 3101-3111. doi: 10.1021/acschemneuro.1c00362

Tran, D., Perrigault, M., Ciret, P., and Payton, L. (2020). Bivalve mollusc circadian clock genes can run at tidal frequency. Proc. Biol. Sci. 287:20192440. doi: 10.1098/rspb.2019.2440

Ulloa, O., Henríquez-Castillo, C., Ramírez-Flandes, S., Plominsky, A. M., Murillo, A. A., Morgan-Lang, C., et al. (2021). The cyanobacterium Prochlorococcus has divergent light-harvesting antennae and may have evolved in a low-oxygen ocean. Proc. Natl. Acad. Sci. 118:e2025638118. doi: 10.1073/ pnas. 2025638118

Wilcockson, D., and Zhang, L. (2008). Circatidal clocks. Curr. Biol. 18, R753-R755. doi: 10.1016/j.cub.2008.06.041

Williams, B., and Naylor, E. (1969). Synchronization of the locomotor tidal rhythm of Carcinus. J. Exp. Biol. 51, 715-725. doi: 10.1242/jeb.51.3.715

Williams, B., and Pilditch, C. (1997). The entrainment of persistent tidal rhythmicity in a filter-feeding bivalve using cycles of food availability. $J$. Biol. Rhythm. 12, 173-181. doi: 10.1177/074873049701200208

Zantke, J., Ishikawa-Fujiwara, T., Arboleda, E., Lohs, C., Schipany, K., Hallay, N., et al. (2013). Circadian and circalunar clock interactions in a marine annelid. Cell Rep. 5, 99-113. doi: 10.1016/j.celrep.2013.08.031

Zhang, L., Hastings, M. H., Green, E. W., Tauber, E., Sladek, M., Webster, S. G., et al. (2013). Dissociation of circadian and circatidal timekeeping in the marine crustacean Eurydice pulchra. Curr. Biol. 23, 1863-1873. doi: 10.1016/j. cub.2013.08.038

Zheng, X., and Sehgal, A. (2012). Speed control: cogs and gears that drive the circadian clock. Trends Neurosci. 35, 574-585. doi: 10.1016/j.tins.2012.05.007

Conflict of Interest: The authors declare that the research was conducted in the absence of any commercial or financial relationships that could be construed as a potential conflict of interest.

Publisher's Note: All claims expressed in this article are solely those of the authors and do not necessarily represent those of their affiliated organizations, or those of the publisher, the editors and the reviewers. Any product that may be evaluated in this article, or claim that may be made by its manufacturer, is not guaranteed or endorsed by the publisher.

Copyright (c) 2022 Rock, Wilcockson and Last. This is an open-access article distributed under the terms of the Creative Commons Attribution License (CC BY). The use, distribution or reproduction in other forums is permitted, provided the original author(s) and the copyright owner(s) are credited and that the original publication in this journal is cited, in accordance with accepted academic practice. No use, distribution or reproduction is permitted which does not comply with these terms. 